\title{
De la difusión cultural de la virtud caballeresca a la defensa del honor ${ }^{1}$
}

\author{
Remedios Morán Martín *
}

\section{RESUMEN ABSTRACT}

A medida que la nobleza va perdiendo su carácter guerrero (bellatores), empieza a elaborar un concepto de virtud y de honor cerceno a las nuevas corrientes humanistas que se difunden en la Península, lo que conileva unas nuevas formas de defensa del honor como práctica social, que desembocarán en la tipificación del duelo como delito.
As the same time as Nobility is on the way to lose its warlike attitude (bellatores), it begins to elaborate a new concept of virtue and honour close to the new humanistic tendencies spread in the lberian Peninsula, what implies new ways to defend the honour as a social practice, which will lead to the typification of the duel as an offense.

Con motivo del quinto centenario del descubrimiento de América La UNED dedicó el monográfico de la Revista A Distancia a tal celebración ${ }^{2}$; Antonio Antelo colaboró en aquel número redactando unas páginas sobre la cartografía del siglo xv y con aquel motivo se resaltó una vez más el rigor con el que abordaba su trabajo. Además, en largas conversaciones con él sobre el reflejo de la conquista de América en la Literatura del momento, que yo esbocé, me introdujo en el mundo de la cultura que él tan bien conocía y al que yo me acercaba con los ojos curiosos del que. cree

* Historia del Derecho y de las Instituciones. UNED.

1 Este trabajo está dentro del Proyecto de Invetigación Complutense, n. ${ }^{\circ}$ PR-52/00-8907, titulado «Las grandes Casas nobles. Identidad, espacio social y formalización institucional del nuevo orden nobiliario (1480-1540)".

a A Distancia, s.n. (marzo, 1993). 
descubrir un nuevo mundo. Me habló de la cultura, de la convergencia y disparidad de la pluma y la espada y de la diferente forma de concebir la verdad al tratar un mismo tema, según la visión particular de cada autor; en este punto me elogió la obra de Victor Frankl ${ }^{3}$ que me llevó a reflexionar sobre esta forma de concebir el relato histórico en el marco de la relatividad y a relacionarlo con el Derecho, que protege en cada momento intereses diferentes, versátil al cambio social que induce a la protección de intereses nuevos.

La extensión del presente trabajo no permite una exposición, ni siquiera breve, de la aportación del significativo número de estudios que se han realizado en los últimos años sobre el tema de la virtud y el honor nobiliarios y de la propaganda de éstos como valores exclusivos de la nobleza, abriéndose en España una línea de investigación que ya había sido iniciada en otros países europeos, especialmente en Italia y Francia.

El objetivo de estas páginas es muy limitado, se trata de apuntar, entre la ficción y la realidad, la relación entre la concepción social de la virtud caballeresca y la elaboración del concepto de honor difundidos por la literatura, que se fragua desde el siglo XII y que en España tiene su máximo desarrollo en el Siglo de Oro, y la tipificación en el Derecho del duelo como delito, lo que nos puede llevar a conocer un aspecto de la cultura de la Baja Edad Media (que marca el ámbito cronológico en el que se ciñe el presente estudio) ${ }^{4}$ y la herencia que ésta deja sobre dicho tema, no resuelta hasta el siglo XIx. El desarrollo jurídico del delito del duelo está siendo objeto de otro trabajo más específico, de pronta publicación.

\section{LA DIFUSIÓN LITERARIA DE UN NUEVO CONCEPTO DE VIRTUD CABALLERESCA DESDE EL SIGLO XII}

Desde mediados del siglo XII asistimos en Castilla a la difusión de nuevos tipos de literatura, que en su conjunto puede denominarse didácticomoral, aunque no sea usual el clasificarla de esta forma en su totalidad, sin embargo, la englobamos como tal dado que el aspecto que aquí interesa destacar es el de la elaboración y difusión de determinados valores:

\footnotetext{
3 V. FRANKL, El «antijovio» de Gonzalo Jiménez de Quesada y las concepciones de realidad y verdad en la época de la contrarreforma y del manierismo, Madrid, 1963.

4 Una síntesis de este tema puede verse en A. ANTELO KGLESIAS, "La cultura española en la plenitud medieval", en Historia General de España y América, tomo IV, Ed. Rialp, Madrid, 1984, 259-395; id., "La cultura», en ibid., tomo V, Barcelona, 1982, 129-188.
} 
Cronológicamente se desarrolla primero el género denominado de caballería a través de la cual se difunde un modelo de conducta del estamento nobiliario que elabora «una visión de la sociedad caballeresca que llegó a superponerse, como una máscara benéfica, a la realidad. La literatura caballeresca comienza por ser una idealización cortés y una sublimación ideológica de los intereses de una clase social amenazada y condenada por el proceso histórico. Es, en su base originaria, literatura con un afán propagandístico y clasista» ${ }^{5}$ en el que se perpetuó el ideal caballeresco y en el cual los humanistas imprimen un sentido mucho más optimista al miedo y la melancolía de la vida característica del hombre del medievo y a la literatura que hasta entonces se había elaborado, donde ocupa un importante lugar el mundo de los sueños, que traslada a la «cultura de la última Edad Media el embellecimiento de la vida aristocrática con las formas del ideal, la luz artificial del romanticismo caballeresco proyectándose sobre la vida ${ }^{6}$ y la práctica de la virtud propia de cada estamento, especialmente de la nobleza, que tiene una importante función en la cual el caballero aparece como un redentor de una realidad dura y sórdida a la que vence. Los valores nobiliarios se elaborarán y difundirán desde la creación de las novelas de temática artúrica, en otros países europeos desarrollada en el siglo XIII, como también en España aparece en este momento, sin embargo se difundirá en nuestro solar a través de las novelas de caballería especialmente a partir del siglo xv y alcanza su apogeo en el siglo XVI, que incluso trasladó su lectura a las nuevas tierras descubiertas en América ${ }^{7}$, hasta que es rechazada a partir de la obra de Cervantes $^{8}$.

Un segundo género literario, íntimamente relacionado con el anterior, denominado en general Specula principis, que viene a coincidir en el mismo fin de trasladar al príncipe o al gobernante un ideal de virtud que debe ser connatural a su forma de vida y de gobierno; coincidiendo con este género, a veces en la misma obra conjuntamente y con entidad propia algo más tarde se elaboran los doctrinales de caballeros (equivalentes a los espejos de príncipes); piénsese entre otros muchos las traducciones en de la primera mitad del siglo XIII de Bocados de Oro, Poridad de po-

\footnotetext{
5 C. García GuAL, «Introducción», en L.A. de CuenCA, Floresta española de Varia caballería, Editora Nacional, Madrid, 1975, 13. También en «Evocaciones caballerescas", en Lecturas y fantasias medievales, Biblioteca Mondadori, Madrid, 1990, 107 y ss.

- J. HuIZINGA, "La nostalgia de una vida más bella», en Revista de Occidente, 28 (abril-mayojunio, 1930), 265-299.

Vid., A. ANTELO IGLESIAS, «De lo medieval a lo renacentista en las letras hispanoamericanas del siglo XVI", en Epos. Revista de Filología. UNED, 5 (1989), 311-315.

8 C. García Gual, Lecturas y fantasías medievales, 19-20.
} 
ridades, el Libro de los doce sabios o Tratado de la nobleza y la lealtad, entre otros, como obras en las que se recogen máximas o sentencias didáctico morales para príncipes y caballeros, sacadas de la tradición oriental o las obras propias como el Libro de la orden de la caballería, de Raimundo Llulio o el Libro del cauallero y el escudero y el Libro de los tres Estados de D. Juan Manuel, por citar dos autores de perspectivas diversas en cuanto a los valores más o menos cercanos al humanismo incipiente en la Castilla del momento, pero con influencia del primero sobre el segundo, lo que demuestra la simbiosis entre los nuevos valores humanistas y la pervivencia de los viejos valores mantenidos mediante la absorción de corrientes ideológicas y la adaptación a las nuevas circunstancias y ya en el siglo xv es imprescindible la referencia al Doctrinal de caballeros de Alonso de Cartagena, manual de conducta caballeresca que pretende una revisión de la normativa sobre el tema ${ }^{9}$ o el Tratado de las armas. Tratado de los rieptos y desafíos de Diego de Valera ${ }^{10}$.

Un tercer género que empieza a difundirse en este momento será el de la biografía, especialmente nobiliaria que tiene un amplio desarrollo en los reinados de Juan II y Enrique IV y que impregna también a la cronística del momento, cuyo paradigma puede ser la Crónica del Rey don Pedro, de López de Ayala; ahora empieza a tratarse también de forma cronística a personajes de la nobleza, como la Crónica de Pedro Niño, la Crónica de don Álvaro de Luna o la Crónica del condestable Iranzo ${ }^{11}$, pero que se había iniciado con anterioridad, en el siglo XIII, con obras como Liber illustribus personarum, de Juan Gil de Zamora o con una obra paradigmática de algunos de los aspectos que aquí se analizan como El Libro d'Alexandre, de género biográfico, pero en el que se aprecian los otros dos aspectos característicos de la época: la recuperación de la antigüedad clásica y la vinculación con la visión cristiana del medievo, lo que determina el tratamiento caballeresco del personaje, cuyas hazañas se desarrollan en el Oriente, dentro de su aspecto mítico, pero cuyo horizonte cultural es el Occidente medieval; si bien este género presenta en Italia un eriorme desarrollo desde el siglo $\mathrm{xv}$, en España tiene unas características diferentes, porque se utiliza como medio de difusión de unos determinados

9 Alonso de Cartagena, Doctrinal de caballeros (ed. de José María Viña Liste, Universidad de Santiago de Compostela, 1995).

10 Sobre la tratadística nobiliaria y especialmente sobre Diego de Valera y los valores nobiliarios, J.D. RodRíguez VELASCO, El debate sobre la caballería en el siglo XV. La tratadística caballeresca castellana en el marco europeo, Junta de Castilla y León. Consejería de Educación y Cultura, Salamanca, 1996.

11 J.L. ROMERO, «Sobre la biografía española del siglo XV», en CHE, I y || (1944), 115-138. 
ideales ${ }^{12}$; estas obras directamente se dirigen a ensalzar los valores nobiliarios y como tal género específico tiene su desarrollo a finales del siglo $\mathrm{xV}$ y especialmente a partir de la segunda mitad del siglo $\mathrm{xVI}$, por lo que ya se sitúa en el límite final del ámbito cronológico que hemos marcado en este trabajo.

Si bien los géneros anteriores tienen su inicio en el siglo XIII, todos vienen a confluir hacia la iniciación desde principios del siglo $x v$ de toda la tratadística nobiliaria, de literatura eminentemente cortesana ${ }^{13}$, impregnada de ideales caballerescos en los que sobresalen el honor, la dignidad, la fidelidad, la prudencia, el linaje, los hechos heróicos, etc.; este género suele redactarse por encargo y tiene como fin legitimar los privilegios nobiliarios y la razón de ser de dicho estamento, como modelo social, ahora en la línea del humanismo que se difunde en la Península. La línea de dicha tratadística ha sido interpretada desde el binomio «la virtud como fuente de la nobleza política» o «la verdadera nobleza está en la virtud moral», dependiendo de las necesidades del grupo en el que está ubicado el redactor de la obra o del cliente para el que se escribe ${ }^{14}$. En todos estos géneros aparece una íntima alianza entre la nobleza y la Iglesia de tal forma que la ideología nobiliaria difundida por la literatura ha sido ampliamente reelaborada y adaptada por los clérigos, hasta este momento monopolizadores de la cultura del Occidente europeo ${ }^{15}$.

A través de este tipo de literatura se va reelaborando y propagando el concepto de virtud (entendida como conjunto de cualidades de transmisión por linaje que abarcaban tanto las personales o morales como las identificadas con el grupo nobiliario que mantenía una situación de prevalencia, así como al conjunto de aptitudes políticas, en sentido amplio), fuente y fundamento de nobleza, pero cuya expresión ya denota un sentido de "hombre nuevo" y cuyos elementos son la prudencia, la templanza y la fortaleza, todo ello dirigido hacia la consecución de la justicia (lejos del

12 Sobre la difusión de los valores nobiliarios a través de las Crónicas y las biografías, vid.,

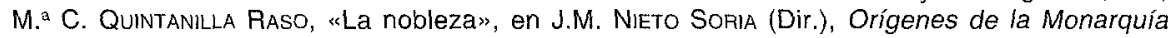
Hispánica: propaganda y legitimación (1400-1520), Dykinson, Madrid, 1999, 70, 73 y ss.

13 No sólo está impregnada de dichos aspectos estrictamente la tratadística nobiliaria, sino también la poesía, como los cancioneros, cfr. el Cancionero de Baena (1445), el Cancionero de Stúniga, el Cancionero de Palacio (1460), etc. o la obra de autores como el Marqués de Santillana - Juan de Mena.

14 J.A. GuILlén BerRendero, Los valores nobiliarios en la Castilla de la segunda mitad del siglo xvi. Los conceptos de virtud y honor en Juan Benito Guardiola y Francisco Miranda Villafañe, Tesina defendida en la Universidad Complutense de Madrid, Facultad de Geografía e Historia, Departamento de Historia Moderna, Madrid, 2000, ff. 33 y ss.

15 J. LE GoFf, La civilización del Occidente Medieval, Barcelona, 1969, especialmente 353 y ss. 
noble altomedieval, más cerca del miles, cuya característica fundamental es el uso de la fuerza); a estos aspectos se van uniendo otros como la destreza en el uso de las armas (durante los siglos anteriores supuesta y ahora explícitamente expuesta) y el cultivo de las letras ${ }^{16}$, lo que daba al noble una especial elocuencia y conocimiento del mundo; al conjunto de cuyos saberes y su interiorización por medio de sus aptitudes éticas se designó cortesía ${ }^{17}$; pero, además, legitimaban su posición de privilegio ${ }^{18}$; finalmente, demuestran una gran preocupación por alcanzar gloria, mediante la realización de hechos heróicos (a imitación de la antigüedad clásica, en gran número de casos citados en la tratadística), aspectos destacados en las biografías de personajes de la nobleza, como «cosa propia de los caualleros» ${ }^{19}$. Tal virtud presenta una simbiosis entre los ideales nobiliarios altomedievales, los valores clásicos ahora recuperados y las matizaciones del cristianismo que modifican a veces sustancialmente unos y otros, subyaciendo en el fondo de toda ella un nuevo concepto de virtud, patrimonio exclusivo de la nobleza, cuya esencia se transmite por el linaje ${ }^{20}$, su galardón es la honra, su reconocimiento público y sostén de su estamento es el honor y ambos sólo al noble corresponde salvaguardar ${ }^{21}$.

La difusión de este tipo de obras dirigido a la clase nobiliaria, ahora refinada y cortés, fue utilizado como forma de propaganda de ideales ya imposibles, enaltecedores de las damas ${ }^{22}$, y que a su vez actúa modifi-

16 Es significativa la alusión de Fernán Pérez de Guzmán refiriéndose al marqués de Villena, a que "naturalmente fue inclinado a las çiençias e artes mas que a la caualleria e aun a los negoçios çeuiles...", en Generaciones y semblanzas (Ed. de Domínguez Bordona, Madrid, 1941), apud., A. Antelo lalesias, "Las bibliotecas del otoño medieval. Con especial referencia a las de Castilla en el siglo XV", en Espacio, Tiempo y Forma, Serie III. Historia Medieval, tomo IV (1991), 307. Veánse también las páginas siguientes sobre las bibliotecas de la nobleza y la amplia bibliografía que incluye.

17 J.A. MARAVALL, "La "Cortesía» como saber en la Edad Media», en Estudios de Historia del pensamiento español, Serie primera, Edad Media, Ediciones de Cultura Hispánica del Instituto de

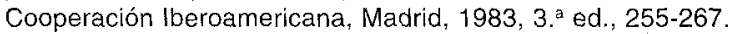

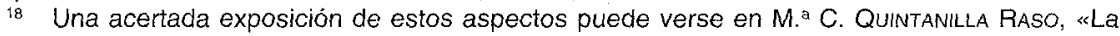
nobleza», en J.M. Nieto SORiA (Dir.), Origenes de la Monarquía Hispánica, especialmente pp. 63-77.

19 J.L. ROMERO, «Sobre la biograíla...», 129-130.

20 Aunque excepcionalmente se establecen mecanismos de acceso a la nobleza, siendo la virtud un conceptos permeable, al que se puede llegar por el esfuerzo personal y por la concesión real. Es una polémica abiesta durante los siglos xv y xVI, que presenta una contradicción entre la defensa a ultranza de los valores individuales de gran número de tratadistas y la mayoritaria oponión de éstos, en sus mismas obras, de la transmisión de la nobleza por el linaje.

21 Claramente es expuesta esta teoría en la obra de D. Juan Manuel, donde se alude a «honra y estado", al deber de "guardar su estado", "llevar su honra adelante», etc.

22 La iglesia va difundiendo una imagen enaltecedora de la mujer como «obra perfecta de Dios" en expresión de Lida de Malkiel, pero en realidad se le está excluyendo jurídicamente, manteniéndola al margen de cualquier actividad mediante un recorte sustantivo de su capacidad de obrar jurídicamente. 
cando el concepto de honor desarrollado en los siglos anteriores de la Alta Edad Media, conllevando, asimismo, una diferente forma de defensa del honor ultrajado, en el momento en el que la Recepción del Derecho Común intenta erradicar las formas altomedievales del proceso para elaborar un nuevo procedimiento.

Debe tenerse en cuenta que ya desde el siglo XIV el «ideal de la caballería» cuya función era el servicio de las armas y la defensa de la sociedad era sólo un arquetipo que quebraba a cada paso mediante las luchas de bandos y se había producido una equiparación entre la caballería de linaje y la caballería villana a partir de las leyes de Alfonso XI, en el que el sentido funcional de la caballería se desdibuja; para I. García Díaz, Alfonso XI sólo mantiene la diferencia entre caballeros de linaje y caballería villana en el tema de la ceremonia de investidura de armas, recuperando un ceremonial al que le infunde un simbolismo perdido, así como también la reanudación en su tiempo de torneos en los que los caballeros se adiestraban en el uso de las armas en tiempos de paz, encaminando con todo ello a destacar los valores éticos-militares de los caballeros encauzando dichos valores hacia una actividad práctica, la guerra con los musulmanes, en un momento de contradicciones en los que los ideales estéticos y formales de la caballería han ido desplazando a su inicial función militar ${ }^{23}$. Esto no mitiga el hecho de que por medio de los géneros literarios apuntados o por medio de los torneos que se celebran durante el siglo XV se intente mantener la idea de unos valores caballerescos enaltecedores del espíritu y la continuidad en la destreza de las armas como formas de vida de la nobleza ${ }^{24}$.

Diferentes autores han analizado el concepto de honor y su identificación a honra ${ }^{25}$ o fama ${ }^{26}$, incluso su equiparación a duelo, como única

23 I. Garcí Díaz, "La política caballeresca de Alfonso Xl», en Miscelánea Medieval Murciana, 11 (1984), 117-133.

24 Sólo a título de referencia los artículos de P. VENTRONE, "Cerimonialtà e spettacolo nella festa cavalleresca fiorentina del quatrocento», el de V. CIRLOT, «EI juego de la muerte. La elección de las armas en las fiestas caballerescas de la España del siglo XV», el de J.E. Ruíz-DoMENEC, «El torneo como espectáculo en la España de los siglos XV-XV'», en La civiltà del torneo (sec. XII-XVII). Giostre e tornei tra Medioevo ed Età Moderna. Atti del VII Convegno di studio, Narmi 14-15-16 ottobre 1988, Centro Stvdi Storici Narmi, 1990, 35-53, 55-78, 159-193, respectivamente.

25 J. Caro Baroja, «Honor y vergüenza», en J.G. Peristiany, El concepto de honra en la sociedad Mediterránea, Nueva Colección Labor, Barcelona, 1968, 77-126, especialmente págs. 8184. CASTRO, AMÉRICO, "Algunas reflexiones sobre el concepto de honor», en Revista de Filología Española (RFE), Madrid, 1916, 2-50 y 117-129.

${ }^{26}$ M. ${ }^{a}$ R. LIDA De MAlkiel, La idea de fama en la Edad Media Castellana, Fondo de Cultura Económica, Madrid, 1983. 
forma de mantenimiento del honor ${ }^{27}$ y la evolución que sufre; se ha defendido que se desarrolla una forma intimista de honor y una forma externa de honra, que a veces se interpreta al revés, siendo el honor la expresión pública de la honra y que en otras teorías se ha equiparado ${ }^{28}$; o evolucionando el concepto de honor hacia la consideración de cristiano viejo ${ }^{29}$; o bien se ha considerado que en la Literatura, dependiendo del género utilizado, el concepto de honor es más o menos riguroso, identificándose honor y fama en el teatro y siendo más estricto aquí que en la novela ${ }^{30}, 10$ que es matizado por $\mathrm{C}$. Chauchadis defiende que la diversidad es tal que hay que analizar cada obra, estudiando tanto el punto de vista desde el que se escribe como el tipo de público al que va dirigida, de modo que existen diferentes formas de presentación del honor en el teatro según se trate de un drama profano, de santos o un drama divino, haciendo tales afirmaciones en el teatro ya del siglo $\mathrm{xVII}{ }^{31}$. En todo caso, hay un punto de coincidencia que destaca no sólo en los distintos géneros literarios, sino también por parte de la tratadística desde el siglo XV: la identificación nobleza-honor, por lo que cuando existe un ultraje al honor, es enarbolado como ofensa a la consideración de la nobleza del ofendido (excepcionalmente por la clase que intenta imitar la vida aristocrática) y a la existencia de una obligación social de la denominada ya en el Siglo de Oro «la venganza del honor» o la «ley del honor», reducto que permanece como específico de la nobleza y que intenta salvaguardar frente a las clases adineradas, pero carentes del honor que les ha sido transmitido por el linaje. La abstracción de los conceptos que se tratan lleva en este punto al cultivo de la fama, que conllevaba un mantenimiento del honor, una adecuada educación en los aspectos concernientes a la virtud nobiliaria que realmente incluía una imitación de los poderes y de las formas de los reyes. Como contrapunto de tales valores, son también los nobles los encargados

27 W.J. ENTwiSTLE, «Honra y duelo», en Romanistisches Jahrbuch, 3 (1950), 404-420.

28 Como en el caso de S. de Covarrubias, Tesoro de la lengua castellana o Española (Ed. preparada por Martín de Riquer, Barcelona, 1943. Ed. Facsímil, Barcelona, Editorial Alta Fulla, Barcelona, 1989, 696 y 697).

29 A. CASTRO, "Algunas observaciones acerca del concepto del honor en los siglos XVI Y XVII, en RFE, tomo III, cuad. 1. (enero-mayo, 1916), 1-50 y cuad. 4. (octubre-diciembre, 1916), 357386. Id. De la edad conflictiva, Taurus, Madrid, 1976, 4. ed.; J. Caro Baroja, «Honor y vergüenza»..., 105. B. BENNASSAR, Los españoles, actitudes y mentalidades, Barcelona, 1978, especialmente Cap. VIII «Del honor a las violencias», págs. 200-221.

30 R. Menéndez Pidal, «Del honor en el teatro español», en De Cervantes y Lope de Vega, Madrid, 1940, 167-169.

31 C. CHAUCHADIS, "El honor, la religión y el mercader. Estudio comparativo de dos comedias de santos: Fray Diablo y el Diablo Predicador. El Diablo Predicador y Mayor Contrario Amigo", en Criticón, 2 (1978), 1-17. 
de "castigar» con la pérdida de honor las contravenciones a las normas propias de la caballeria, haciendo incurrir en deshonor, hecho público mediante la reversión del escudo de armas ${ }^{32}$.

Así mismo se produce una evolución semántica desde desafío a duelo y su recepción en la literatura que ha sido ampliamente estudiada por $\mathrm{C}$. Chauchadis, que si bien centra su estudio en los siglos XVI y XVII es esclarecedor en gran parte de los temas que aquí se señalan, puesto que incide en la evolución semántica, pero que va detrás de la evolución hacia la práctica del duelo y el "código de honor» como recurso ajeno al desafío y riepto, pero identificado popularmente como desafío. Él retoma las definiciones de nuestro ordenamiento para concluir que la expresión duelo en la España del siglo XV y XVI era la reflejada por Covarrubias, dolor, que sólo desde Alonso de Cartagena, en el Doctrinal de Caballeros, se empieza a utilizar duelo como batalla de dos, cuando hasta entonces se habían utilizado los términos de lid o batalla, utilizando la expresión duelo para referirse a «dolor», tal como recoge Covarrubias. A partir de la edición en 1525 del Tractatus del duello, de Diego del Castillo, traducida con el título Remedio de desafíos, empieza a traducirse sistemáticamente duelo por desafío, de esta manera va penetrando la identificación de ambos, que no son idénticos, siendo el duelo solemne, mientras que el desafío es familiar, secreto ${ }^{33}$.

Sin embargo, la práctica del duelo tal como nos ha quedado en la literatura y su enorme difusión para Chauchadis está en la recepción de la figura italiana, por medio de los soldados que participan en las campañas de Italia, prácticas que se difunden a raiz de la publicación en 1472 de la obra de Paris de Puteo De re militari ${ }^{34}$, publicada en Italia con el título de Duello y en España con el título Libro llamado batalla de dos. Éste y otros tratados sobre el duelo, ahora retomando formas de la antigüedad clásica ${ }^{35}$, se circunscriben fundamentalmente a la alta clase nobiliaria, por lo que

32 Algún ejemplo de estas prácticas es expuesto por M. DE R!QUER, Caballeros medievales y sus armas, Instituto Universitario «General Gutiérrez Mellado», UNED, Madrid, 1999, 93.

33 Chauchadis, C., La loi du duel. Le code du point d'honneur dans I' Espagne des XVleXVIle siècles, Presses Universitaires du Mirail, Toulouse-Le Mirail, 1997, 27-41; id., "Libro y leyes del duelo en el Siglo de Oro", en Criticón, 39 (1987), 77-113, especialmente 78-79.

34 Sobre traducción de esta obra y la difusión en España, vid. M. ${ }^{a}$ del P. CARCELLER Cerviño, Diego Enriquez del Castillo y la tratadística caballeresca castellana del siglo xv: De re militari de Paris de Puteo, Tesina presentada en el Departamento de Historia Medieval, Universidad Complutense de Madrid, enero de 2000.

35 A. Gómez MOReno, «La militia clásica y la caballería medieval: las lecturas de re militari entre el Medievo y Renacimiento», en Evfhrosyne. Revista de Filología Clássica, nova série, vol. 23 (1995), 83-97. 
es esencial la publicidad, y se rechaza el desafío privado, retomando en esencia las viejas prácticas medievales del riepto y desafío de nuestro Derecho, si bien sin intervención pública y aunque es cierto que se habla de la moderación en el uso y el seguimiento de determinadas reglas, o el uso del mismo como último recurso, lo cierto es que se utilizó muy frecuentemente ${ }^{36}$, identificándose cada vez más las leyes del duelo con las leyes del punto de la honra y entroncando ésta con la venganza de las injurias, de tan larga tradición en nuestra historia.

Esto lleva a la creación de una ley paralela, recogida en lo que se llamó Código de honor.

\section{LA DEFENSA DEL HONOR}

\subsection{Inimicitia: la ruptura de la amicitia en la Alta Edad Media}

Hay que retrotraerse a la pérdida de paz (inimicitia) y venganza de la sangre o ejecución privada de la justicia de nuestra Alta Edad Media: cometido determinado delito (especialmente de sangre o contra el honor) la parte ofendida tiene derecho a declarar la enemistad y consecuencia de ello es la posibilidad de ejercer la venganza sobre el ofensor que desde ese momento es inimicus. Son los delitos de sangre y contra el honor, los que generan la pérdida de la paz y la venganza de la sangre; un primer recorte de la venganza privada está en la necesidad de declaración expresa de pérdida de la paz, mediante un diffidamentum (o declaración pública de ruptura de la amistad especialmente pactada o la paz general que existía entre los nobles), a partir de la cual el ofensor se convertía en enemigo manifiesto o conocido.

Las ofensas al honor, tanto de palabra como de obra, están consideradas en los fueros como hechos punibles, entre los que destaca el arrancar

${ }^{36}$ Ibid., "Libro y leyes del duelo...», 82-85. Sobre la influencia italiana en el modo de concebir el honor en el teatro, especialmente de Calderón, se han hecho distintos estudios, en torno a la defensa o a la condena que plantea nuestro máximo autor de los dramas de honor, a título de ejemplo véase, Calderón de la Barca. Dramas de honor (Edición, prólogo y notas de Angel Valbuena Briones, Espasa Calpe, Madrid, 1967, XIV-XXXVII). Distintos puntos de vista sobre el tema, en El postrer duelo de España (Edited with Introduction and Notes by Guy Rosetti, Tamesis Books Limited, London, 1977, especialmente págs. 29-45) y C. CHAUCHADIS, "Las denuncias de la ley del duelo en El postrer duelo de España. Nuevo examen", conferencia pronunciada en la Casa de Velázquez, Madrid, 1-VII-92, dentro del Seminario de Investigación «Historia de la España Moderna: La comedia», texto mecanografiado. Agradezco al profesor Chauchadis que me facilitara el texto de dicha conferencia, además de las sugerencias sobre el tema. 
la barba o la cabellera, así como tocar la barba con intención ofensiva, por considerarse signos de virilidad ${ }^{37}$. Argumenta J. Orlandis que la gravedad de los delitos estaba en relación con el círculo de personas a las que afectaban de tal forma que «los delitos especialmente graves originaban un estado de pérdida general de la paz, en virtud del cual quedaba su autor falto de protección frente a toda la comunidad política de que formaba parte, y su castigo. Equivalía esta situación a una pena de muerte cuya ejecución no se reservaba a la autoridad pública. Más reducidos eran los efectos del segundo grupo de los delitos que causaban quebrantamiento de la paz; faltaba en ellos la circunstancia que le hiciera, como a los anteriores, particularmente odiosos, y por ello las consecuencias de aquella ruptura eran más limitadas; el estado de indefensión jurídica del autor dábase solamente frente a un determinado grupo de personas, las directamente ofendidas por el delito, que podían ejecutar legítimamente la llamada venganza de la sangre, mientras el poder público y los demás miembros de la comunidad permanecían en una actitud puramente pasiva, absteniéndose tanto de participar en el castigo como de oponerse a él»» ${ }^{38}$. Si tuviéramos que ejemplarizar en una obra el sentido de esta forma de restauración de la ruptura de la paz, tendríamos que citar como obra específica la Leyenda de los Siete Infantes de Lara o algunos de los aspectos dichos reflejados en el Cantar de Mio $\mathrm{Cid}^{39}$. Como consecuencia de estos actos de ruptura de la paz se fue elaborando un procedimiento que, una vez reglado, conocemos como desafío y riepto y que $M$. Torres estudió y diferenció claramente del duelo ${ }^{40}$. Este antiguo procedimiento de desafío y riepto, alcanzaba sólo a los delitos de traición y alevosía ${ }^{41}$.

Llegados a este punto, no puede olvidarse la intensa labor legislativa de Alfonso $X$ que intenta recortar la ejecución privada de la justicia y en especial, en el tema que nos ocupa, la regulación de los casos de Corte en el Ordenamiento de Zamora de 1274, en el que precisamente atrae

37 E. DE Hinojosa, El elemento germánico en el derecho español, Madrid, 1915 (también en Obras, I, Madrid, 1955 y ed. facsímil, Marcial Pons, 1993); id., «El Derecho en el Poema de Mío Cid», en Obras, 1, Madrid, 1948, 205-206. G. SÁNCHEz trata en su breve estudio del delito de adulterio y de las facultades concedidas al marido ofendido en «Datos jurídicos acerca de la venganza del honor", en Revista de Filología (RF), tomo IV, cuaderno 3. ${ }^{\circ}$ (julio-septiembre, 1917), 292295.

38 J. ORLANDIS, "Sobre el concepto de delito en el derecho de la Alta Edad Media», en Anuario de Historia del Derecho Español (AHDE), 16 (1945), 124-125.

39 Vid., vv. 3.256-3693.

40 M. TORRES, «Naturaleza jurídico-penal y procesal del desafío y el riepto en León y Castilia en la Edad Media», en AHDE, 10 (1933), 161-174.

41 Sobre éstos, véase J. García GonzÁlez, "Traición y alevosía en la Alta Edad Media», en AHDE, 32 (1962), 323-345. 
hacia la jurisdicción real los delitos incluidos en el concepto de traición y alevosía, pero además, todos los que suponían delitos contra la vida, el honor y todos los cometidos por infracción de una paz especialmente pactada ${ }^{42}$. Estos recortes pudieron derivar hacia el desarrollo paralelo de la defensa privada de los delitos contra el honor, con formas similares a las antes realizadas bajo la tutela del rey o el juez, cuando la autoridad pública atrajo para sí la protección de dichas ofensas que, sin embargo, socialmente no satisfacía la demanda que los mismos requería, de forma similar a la que aparece en los textos de carácter local donde se aprecia la separación entre la composición pagada a la parte ofendida en concepto de pena pecuniaria y la persistencia de la venganza de la sangre ${ }^{43}$, a lo que se unió un nuevo concepto de honor, más cercano a la clase nobiliaria y a las nuevas funciones que la misma va ocupando como modelo de referencia, más que como estamento dedicado a las armas, cuyo cometido había sido sensiblemente menguado por la nueva administración que estaba emergiendo.

\subsection{Del desafío y riepto al duelo}

El desafío y riepto están recogidos tanto en textos de carácter local como territorial, a modo de referencia aludo sólo a la obra legislativa de Alfonso $X$ donde se recoge en Partidas, $7.3 .1^{44}$ y lo completa el Fuero Real, $4.21 .1^{45} ; 4.21 .2^{46} ; 4.21 .6^{47}$ y posteriormente en época de Alfonso XI

42 "Estas son las cosas que fueron siempre usadas de librar por corte de Rey: muerte segura, muger forzada, tregua quebrantada, salvo quebrantado, casa quemada, camino quebrantado, traycion, aleve y riepto", Cortes de los antiguos reinos de León y Castilla (CLC), Real Academia de la Historia, Madrid, 1861, I, 94.

43 Vid. E. DE HiNojosA, El eiemento germánico, 43,54 y ss

44 «Riepto es acusamiento que faze un fidalgo a otro por Corte profaçándolo de la traycion, o del aleue que le fizo"

45. «Antiguamente los fijos-dalgo, con consentimiento de los Reyes, pusieron entre sí amistad, e dieronse fé unos a otros de la tener e guardar de no se facer mal unos a otros a menos de se tornar ante amistad e de se desafiar; e por ende quando algun fidalgo en razon de caloñar a otro por tuerto que le haya fecho, debele tornar amistad: e la fe quel torna quando le desafía es la que fue puesta antiguamente, así como sobredicho es: e desde aquel día quel desafía, no le ha de facer mal fasta nueve días".

46 «Todo fidalgo que a otro fidalgo matare o lisiare o le presiere, o le firiere, o corriere con él ante que le haya desafiado es por ende alevoso e tal dicho como este es llamado riepto"

47 «Quienquier que a otro reptar quisiere, debele reptar en esta guisa: fagalo llamar ante el rey, e despues que fuere delante del Rey, diga el fecho porque le riepta e digale que es ende alevoso, e que gelo fará decir, o le matará o le porná fuera del plazo: e si ge lo quisiere probar por testigos, o por carta, o por pesquisa del Rey, dígagelo, y el reptado dígale que miente: e si quisiere combatir dígalo, e si no quisiere combatir, diga que fará quanto el Rey mandare, e su Corte». 
se reitera en el Ordenamiento de Alcalá de 1348, recogido del Pseudoordenamiento de Nájera.

La naturaleza de los mismos han sido suficientemente estudiadas por los profesores Torres López, Otero Varela o aportaciones de otros autores como Paulo Mêrea y Cabral de Moncada ${ }^{48}$.

Para Torres hay una sensible diferencia entre desafío, riepto y duelo; sólo recojo sus conclusiones con el fin de clarificar este estudio y diferenciar las épocas:riepto "aparece sencillamente, y ésta es su verdadera naturaleza jurídica, como un procedimiento especial ante la Curia del rey al que debe acudirse en los casos de traición y alevosía. Es un procedimiento especial en dos aspectos: uno por ser ante la Curia regia, otro por no alcanzar sino a los delitos de alevosía y traición». Desafío «no es otra cosa sino la denuncia de la fe o amistad establecida con carácter general entre los fijosdalgo en virtud de disposiciones de tipo público, de acuerdo común ratificado por el rey. Este acuerdo no es sino una tregua o paz, una tregua general de carácter nobiliario". En el caso de no hidalgos, la alevosía la provoca la falta a una fe especialmente pactada, no la general de los hijosdalgo. Por lo tanto el riepto no es el duelo, podría, sin embargo, decirse que sin ser el duelo mismo, al terminar el riepto con un combate judicial, cabría mediante una traslación filológica y de contenido, llamar al duelo riepto y suponer a éste tal. Esto no es posible porque el riepto no siempre terminó, legalmente no tenía que terminar con un combate judicial. «El combate judicial fue en el riepto sencillamente una de las formas de prueba a que podía acudirse para probar la verdad o falsedad del riepto. Ni fue más ni fue menos y así resulta que el papel de la batalla judicial en el riepto no fue sino el mismo que en los procedimientos medievales desempeñó el juicio de batalla, de modalidades tan diversas y tan por estudiar entre nosotros, a pesar de la riqueza de fuentes para su conocimiento» 49 .

Otero Varela también dedicó un importante estudio al riepto tanto en los textos de carácter real, como en los fueros municipales. Esencialmente

48 Sobre el duelo como medio de prueba, con diferencias respecto a Torres, vid., P. MERÉA, "Juramento e duelo nos foros municipais», en História e direito (Escritos dispersos), Tomo I, Coimbra, 1967, 135-150; id., "O Poema do Cid e a história do duelo", en ibid., especialmente pág. 67 y ss.; id, "Composiçao corporal (Achêga para a historia do direito penal portugués), AHDE, 15 (1944), 564-570. N. ALCALÁ-ZAMORA Y CASTILLO, «Instituciones judiciales y procesales en el Fuero de Cuenca", en AHDE, 12 (1982), 99-102, él mismo destaca cómo se aprecian otras posibilidades de resolver el conflicto, mediante pruebas distintas, en ibid., 99, nota 123; R. PrIETO, "Carta de avenencia entre hidalgos", en AHDE, 5 (1928), 431-434. L. CABRAL. DE MONCADA, "O duelo na vida do direito", en AHDE, 2 (1925), 213-232 y 3 (1926), 67-88, especialmente, pág. 70.

49 M. ToRres, "Naturaleza jurídico-penal y procesal del desafío y el riepto...», 167 y 170-172, 
sigue la teoría expuesta por Torres sobre la diferenciación entre riepto, desafío y duelo, pero no coincide con Torres en dos puntos: primero en cuanto a las personas que pueden acogerse al riepto, puesto que para Otero es un procedimiento exclusivamente para hidalgos, por tanto regulado casi exclusivamente en los textos reales, tanto de carácter territorial como local arriba mencionados. En cambio, cuando en diversos textos de carácter local se trata del riepto, no se asemeja al riepto de los hijosdalgo sino en el empleo de la lid, existiendo diferencias sustanciales entre uno y otro. Para Otero "el riepto municipal y el riepto de los hijosdalgo son dos instituciones distintas con la misma denominación. La identidad de nombre quizá encuentre su razón de ser en el posible origen común de ambos rieptos. Este origen no puede ser otro que el duelo. El duelo es, desde el siglo $\mathrm{Xl}$, una de las instituciones más generalizadas, aunque con distintas modalidades y produciendo distintos efectos jurídicos».

En segundo lugar, entre la teoría de Torres y la de Otero hay una divergencia esencial, que se puede resumir en la diferenciación por parte de éste de dos tipos de rieptos, uno entre hijosdalgos y otro general, regulado por los fueros municipales. Desde el punto de vista del duelo para Otero hay, además, otra diferencia esencial entre el riepto de los hijosdalgo y el riepto municipal: el duelo de los concejos tiene un carácter de ordalía, un simple medio de prueba, que nunca adquirió el duelo de los hijosdalgo. Esta diferencia se debe al desarrollo en medios sociales distintos: «No sería natural que el duelo de los nobles adquiriese el carácter de juicio de Dios junto al rey, en la Corte, donde era más eficaz la influencia del clero con su repugnancia por aquellas formas procesales. Así terminó por ser exclusivamente un medio de atestiguar solemnemente con honra y caballerosidad la firmeza de convicción con que es acusado o se defiende un caballero sobre el que recae una acusación de traición o aleve», en este sentido, el riepto municipal sería un estadio anterior del riepto entre hidalgos, después regulado en los textos alfonsinos y en el Ordenamiento de Alcalá. Y, además, evolucionó de distinta manera, reduciéndose el del concejo a una prueba ordálica en distintos procedimientos especiales, cuando los delitos de que se acusa son más graves, singularmente en los delitos de falso testimonio y otros de calumnias, siendo alternativo el juramento como medio de prueba en los delitos menos graves. El riepto de hijosdalgo es un procedimiento especial del Tribunal de la Corte para casos de traición y aleve, derivados de la violación de la concordia establecida entre hijosdalgo ${ }^{50}$. Sin

50 A. OTERo VARELA, «El riepto en el derecho castellano-leonés», en Dos estudios histórico-jurídicos, Roma-Madrid, 1955; id., «El riepto de los fueros municipales», en AHDE, 29 (1959), 153-173. 
embargo Torres defiende la forma única de riepto, con un procedimiento solemne especial en caso de nobles, y siempre siendo el duelo un medio de prueba. En este punto incide J.M. Pérez-Prendes, analizando una sentencia arbitral en la que a través de la espiritualización de una lid, en caso de incumplimiento de la sentencia, da pie a la consideración del final de una institución ya en plena Recepción del Derecho Común (1404) ${ }^{51}$.

Considero que la teoría de Torres tiene una mayor fundamento, si bien es cierto que fue erradicándose el riepto en los concejos permaneciendo exclusivamente el procedimiento solemne especial de los nobles que también deja de utilizarse paulatinamente y en la práctica es una institución ya excepcional en el siglo $\mathrm{xV}$.

A partir de este momento se aprecia paralelamente a la regulación del desafío y el riepto solemne, el desarrollo de la práctica social del duelo (diferente a la lid como medio de prueba o como resolución judicial de un delito de traición y aleve), con un ritual que se aparta de la forma procesal de los anteriores, desarrollándose socialmente como medio de protección del honor, como una acción contra legem. La disparidad entre la legislación y la práctica se constata claramente cuando se analizan tratados sobre la nobleza o sobre las armas en los cuales se desarrolla ampliamente el ritual del duelo y obras en las cuales el sentido procesal del desafío y riepto ha sido olvidado, aunque no fue derogado. La resolución de lo que se consideraba actos contra el honor entre nobles llegó a ser tan generalizada que desde Juan II se tipifica el duelo como un delito, mediante la prohibición de la resolución privada de conflictos entre hijosdalgo con la forma que fue adquiriendo desde el siglo XIv, principalmente.

No se ha realizado un estudio jurídico de la evolución que sufrió el desafío y riepto como procedimiento hacia el duelo como delito, no obstante los autores que han aludido al tema consideran que fue erradicándose. Así, Tomás y Valiente, basándose en Diego de Valera y en Alonso de Cartagena, señala que el desafío y riepto fue perdiendo terreno en Castilla y dejando paso hacia prácticas de tipo privado, pero además, teniendo en cuenta las obras de éstos considera que hacia mediados del siglo XV, ellos no conocen directamente la institución del desafio y riepto como practica-

\footnotetext{
51 «E demays, que aquel que o contrario d'esto fiser e o non teuer o comprir e agardar, que aquel que o tiuer e compryr e agardar, con outro parçoeyro de caualo armados de todas armas, seas queseren leuar, posam diser aa outra parte que o outro home alguno, desarmado sem arma ninhuna commo aquel que non tem verdade nem juramento que sobre elo feso" J.M. PÉREZ-PRENDES, "Sobre prenda extrajudicial, alevosía y riepto», en Anuario Jurídico Escurialense, 15 (1983) 89-95.
} 
das y vividas, sino a través de los textos de Partidas y Ordenamiento de Alcalá, de modo que Diego de Valera en su Tratado de los desafíos y rieptos sólo dedica varias páginas al uso de las armas, sin realmente tratar el tema, lo que él vive son las «enpresas» y «requestas», amistosas $u$ hostiles, contra las que va Juan II y por tanto, lo que hacen los Reyes Católicos en la ley 89 de las Cortes de Toledo de 1480 no es derogar el riepto, sino prohibir los duelos privados, ajenos al riepto ${ }^{52}$.

La práctica del duelo ya la quiere erradicar tanto Partidas como Fuero Real, pero será Alfonso XI quien ante las continuas contravenciones a los textos anteriores intente de nuevo que las enemistades entre los hijosdalgo se resuelvan ante el rey, según Derecho en el Ordenamiento de Cortes de Burgos de 1338 , leyes $1-11^{53}$ y después explícitamente Ordenamiento de Alcalá, que deroga el anterior ${ }^{54}$. El mismo espíritu se recoge en el Ordenamiento de Montalvo, 4.2 .1 y en la Recopilación de Felipe II, 6.2.1, que tratan de la paz entre hijosdalgo, estractadas del Ordenamiento de Alcalá, 32.46 (ley no recogida en Novísima Recopilación) y remitiendo al procedimiento reglado del desafío y riepto.

El duelo como práctica alejada del desafio y riepto explícitamente lo prohíbe Juan II (está recogida dicha prohibición en el Ordenamiento de Montalvo, 4.9.8, que la fecha en Madrigal, en 1438; y en la Recopilación, 8.8.9, que la fecha en Tudela, en 1409; no se incluyó en la Novísima Recopilación) y posteriormente reiteran dicha prohibición de duelos privados los Reyes Católicos, con algunas diferencias, en la ley 87 de las Leyes de Toledo de 1480 (también incluidas en el Ordenamiento de Montalvo, 4.9.11; en la Recopilación, 8.8.10 y en la Novísima Recopilación, 12.20.1).

La inclusión de dichas leyes en el Ordenamiento de Montalvo, en el libro cuarto, dedicado a los caballeros y en la Recopilación, no ya en el libro y título sobre los hidalgos, sino el libro octavo, dedicado al Derecho

52 F. TOMÁs y VALIENTE, El derecho penal de la monarquía absoluta (siglos XVI, XVII y XVIII), Tecnos, Madrid, 1992, 51-56.

53 Se reitera en diferentes leyes, pero el espíritu se sintetiza en la ley 6 del Ordenamiento de Cortes de 1338: «Otrosi que los rrieptos que son començados fasta aqui, quelos libremos nos con fuero e con derecho segund quelo libramos fasta aqui». Asimismo, se regula de nuevo el desafío en las leyes 1 y $9, C L C, 1,444-449$.

54 Al tratar de la amistad de los Fijosdalgo, dice que «por raçon de escusar muertes, è desonrras, è desheredamientos, è por sacar males de los fjjosdalgo d'Espanna que puso entre ellos pas, e sosegamiento è amistat... que ningunt fijodalgo non matase, ni firiese vno a otro, nin corriese, nin desonrrase, nin forcase vno à otro, à menos de se desafiar, è tornarse la amistat que fue puesta entrellos..." y el que lo contrario hiciere fuere por ello alevoso, Ordenamiento de Alcalá, 32.46 . 
procesal y penal, lo que es indicio de que la persecución penal del duelo estaba plenamente consolidada, en ambos casos preceden las leyes que regulan el desafío y riepto, tomadas del Fuero Real y del Ordenamiento de Alcalá.

La ley de Juan II se refiere principalmente a hijosdalgo, pero, además, reconoce la práctica del duelo por villanos, castigando con distintas penas a unos y otros en atención a la clase social como causa modificativa de la capacidad de obrar.

De esta prohibición se deduce la práctica de un desafío extrajurídico, pero sin apenas expresión de su forma, extremo que se recoge más explícitamente en la siguiente ley de la Recopilación, que incluye la ley de los Reyes Católicos, dada en las Cortes de Toledo de 1480, en la cual se describe el uso de enviar carta retando y se penaliza más gravemente que en tiempos de Juan II, adecuando la pena según el grado de participación en los hechos ${ }^{55}$.

La diferencia esencial entre una y otra ley está en que en la ley de los Reyes Católicos se tipifica un delito: el desafío y duelo privado, no la petición o invitación (reqüesta) a la contravención a las leyes del desafío y riepto solemne ante e! rey, que es lo que prohibe Juan II. Es un delito, no un agravamiento del homicidio, puesto que éste está regulado posteriormente y en otro título, el 22 , de los homicidios, en la Recopilación y en Novísima Recopilación, 12.21.

55 Recogida en Novísima Recopilación, 12.20.1."Una mala usanza se freqüenta agora en estos nuestros reynos, que quando algun Caballero ò Escudero, ò otra persona menor tiene queja de otro, luego le envie una carta, que ellos llaman cartel, sobre la queja que dél tiene; y desta y de la respuesta del otro viene á concluir, que se salga a matar en lugar cierto, cada uno con su padrino ó padrinos, ó sin ellos, segun que los tratantes lo conciertan: y porque esto es cosa reprobada y digna de punición, ordenamos y mandamos que de aquí adelante persona alguna, de qualquier estado y condicion que sea no sea osado de facer ni enviar los carteles á otro alguno, ni lo envie á decir por palabra; y qualquier que lo contrario hiciere, siquier sean dos ó muchos, cayan é incurran por ello en pena de aleve, y hayan perdido y pierdan por ello todos sus bienes para la nuestra Cámara; y el que rescibiere el cartel, y aceptare la respuesta, haya perdido y pierda todos sus bienes para la Cámara, aunque trance y pelea no venga en efecto; y si dello se siguiere muerte ó feridas, y el reqüestador quedare vivo de la reqüesta ó trance, muera por ello, y si el reqüestado quedare vivo, sea desterrado del reyno perpetuamente. $Y$ porque en los tales delitos tienen gran culpa y cargo los tratantes, que llevan y traen los mensages y carteles desto, y los padrinos que usan con ellos; mandamos, que ninguno sea osado de ser en esto tratante, ni llevar ni traer los carteles y mensages, ni sean padrinos del tal trance ó pelea; so pena que por el mismo fecho caya é incurra cada uno dellos en pena de aleve, y pierda todos sus bienes, y sean las dos tercias partes para la nuestra Cámara, y el otro tercio para la persona que lo acusare, y para el juez que lo sentenciare: y que los que miraren, y no lo despartieren, pierdan los caballos y mulas en que fueren, $y$ las armas que llevaren; y si fueren á pie, que pague cada uno seiscientos maravedís, y que estas penas se repartan en la forma susodicha». 
Asimismo, ha desaparecido toda referencia a los dos casos que recogía el reglado desafío y riepto (traición y aleve), para referirse a práctica generalizada sobre cualquier asunto, la simple «queja».

Por otra parte está claro que se usa con frecuencia la forma privada de venganza, a tenor del agravamiento de las penas (incluso el mero intento), y de la minuciosidad en la regulación de los grados de participación, contraponiéndose a la práctica habitual en este momento, que no suele descender a la descripción de estos aspectos, salvo en casos excepcionales. Por otra parte, el contenido de la ley de 1480 difiere sustancialmente de los antiguos rieptos, tanto en el procediminto (antes solemne y legalmente regulado), en la autorización real (ahora inexistente), en los motivos (antes traición y aleve, ahora simples quejas) ${ }^{56}$.

Existen otras diferencias entre la ley de Juan II y la dada por los Reyes Católicos en las Cortes de Toledo: en primer lugar, el delito tipificado en 1480 es la mera convención para matar, con o sin padrinos, individualmente o en grupo, se llegue o no a realizar la lucha; en segundo lugar, no existe en la ley de los Reyes Católicos alusión a diferencia de estamentos, por lo que no hay una modificación de las penas en relación con éstos, como la hay en la graduación de Juan II, en la que se aplica incluso pena corporal y degradante (cien azotes), en caso de que el requestador sea villano; en tercer lugar, los Reyes Católicos graduan la pena, castigando más severamente al retador que al retado, por lo que se valora la iniciativa en la comisión del delito; también, se graduan las penas para los participantes, colaboradores necesarios, según las leyes del duelo, en la ejecución del delito, tanto facilitando el acuerdo de las partes, como actuando de simples espectadores, lo que incide en la necesidad de erradicar el duelo mediante el agravamiento de las penas y la tipificación de toda participación; finalmente, en la ley de Juan II se hace mención de empressa ò requesta entre hijosdalgos o entre villanos, como simple invitación sin aludir a forma, sin embargo, en la ley de los Reyes Católicos sí se alude al envío de carteles en los cuales se recogía el motivo de la queja y la forma en la que se realizaria el duelo; éstos solían ser frecuentes y dieron lugar a un profuso género que ha sido estudiado ${ }^{57}$.

56 F. Tomas y VALIENTE, El Derecho penal..., 55. Respesto a las personas, que dicho autor considera son exclusivamente nobles en el antiguo riepto, difiere $M$. TORRES, «Naturaleza jurídicopenal...», 170-171, donde demuestra que a tenor de la regulación de la figura en el Fuero Real, pueden retar personas distintas a hidalgos.

${ }^{57}$ Vid., M. DE RIQUER, Lletres de batalla, cartells de deseiximents i capitols de passos d'armes, 3 tomos, Colección «Els Nostres Clàssics», Barcelona, 1963-1968. A. GOMEZ MORENO, «Pleitos familiares en cartas de batalla», en Bandos y querellas dinásticas en España al final de la Edad 
En ninguna de las leyes citadas se deroga formalmente el antiguo desafío y riepto, pero éstos posiblemente ya en época de los Reyes Católicos estaban en desuso. Según Chauchadis, el riepto autorizado por Carlos V en 1522, que relata el cronista Fr. Prudencio de Sandoval, y que con algunas diferencias recoge Calderón de la Barca en El postrer duelo de España, es el último desafío a duelo solemne según las leyes de Castilla, si bien parece ya un duelo influido por la moda italiana, en una época en la que ya los duelos secretos eran los habituales ${ }^{58}$, y así lo recoge la literatura, los avisos de corte, crónicas locales, etc.

No fueron estas leyes los únicos intentos de erradicar la venganza privada de las ofensas, a nivel eclesiástico fue prohibido el duelo en el Concilio de Trento con penas espirituales y temporales para los duelistas, también Felipe II aportó su eslabón en esta cadena de prohibiciones, según constitución de 1560, capítulos 6 y 8 para la toma del hábito de la orden de Santiago, no admitiendo a caballeros que hubieran participado en duelos, así como las leyes de Felipe $\mathrm{V}$, cuyo análisis está incluido en el trabajo que preparo sobre el delito del duelo.

\section{CONCLUSIONES}

Desde mediados del siglo XIV y durante el siglo XV se produce en toda Europa una eclosión de obras sobre la virtud caballeresca, el honor militar (referido al honor caballeresco) y la defensa del mismo mediante el duelo. En el trasfondo de tal fenómeno estaba el cambio socio-cultural que se estaba produciendo en este momento en el cual se estaba pasando del valor militar de la nobleza hacia los valores éticos y culturales de éstos, referente del resto de los estamentos, especialmente de grupos que en este momento empiezan a obtener poder dentro de los cargos de la administración, como pueden ser los letrados ${ }^{59}$, por lo que en gran medida será la idea elaborada y difundida por éstos de que la virtud se alcanza no sólo por el manejo de las armas, sino también por el conocimiento y el desarrollo del espíritu mediante la educación la que iría en cierto modo transformando el concepto de honor y fama y, consecuentemente, su defensa.

\footnotetext{
Media. Actas del Coloquio celebrado en la Biblioteca Española de París los días 15 y 16 de mayo de 1987, Cuadernos de la Biblioteca Española, n. ${ }^{\circ}$ 1, París, 1991, 95-104. A. Orejudo UTriLla, Cartas de batalla, Edición, introducción y notas, Ed. PPU, Barcelona, 1993.

58 C. Chauchadis, «Las denuncias de la ley del duelo en «El postrer duelo de España».

59 Sobre este tema, vid., M. ${ }^{a}$ C. QUINTANILLA RASO, "La nobleza en la historia política castellana en la segunda mitad del siglo XV. Bases de poder y pautas de comportamiento", en Congresso Internacional Bartolomeu Dias e a sua época, I, Porto, 1989, 189-190.
} 
Posiblemente, el concepto de honor caballeresco, que tan frecuentemente lo encontramos en la literatura de estos siglos, sin grandes similitudes con el primitivo concepto de honor, más cerca de la honra, en cuanto a opinión que los demás tienen, parta de textos autóctonos como el de Partidas, 2.21.25, en el que se recogen las características del perfecto caballero, que si pierde su caballería, entre otros motivos, no podrá reptar. Esta moral caballeresca y la defensa del honor, especialmente entre caballeros, aunque se trasladó a otras clases ciudadanas, se difunde en obras como las de Raimundo Lulio, Libro de la Orden de Caballería, Juan Manuel, Libro del Caballero y el Escudero, o también en parte del Libro de los Estados, Alonso de Cartagena en Doctrinal de Caballeros, que más tarde se van a ir aderezando con manuales de destreza de armas, como el de Diego de Valera, Tratado de las armas, tratado de los rieptos y desafíos, y una larga lista de tratadistas que centran sus obras sobre el tema, estimulando la creación, en parte propia, en parte importada de las modas francesa e italiana, de un "código de honor», de obligada exigencia social, prohibido por la leyes, y obviado por los tribunales hasta bien entrado el siglo XVIII.

Realmente, riepto y desafí, por una parte y el duelo paralelo a aquellas formas regladas, va evolucionando a medida que evoluciona la sociedad, el concepto de honor y los medios de defensa de éste, llegándose a confundir por la tratadística nobiliaria el procedimiento especial y el delito, para defender por éste lo que para determinados casos estaba salvaguardado por aquél. Quizás el problema no estuviera en la defensa del derecho al honor por vía jurisdiccional, que estaba regulado de forma diferenciada a desafío y riepto, sino en la creación de un concepto de honor que cada vez se identificó más con unas reglas que debían aplicarse fuera del ámbito jurisdiccional, por exigencia social, llegándose a identificar honor y duelo.

Esta desviación está relacionada con el concepto de honor que se va creando y desarrollando, principalmente entre los hidalgos, desde la Baja Edad Media, que se desarrolla ampliamente en los siglos XVI al XVIII y que resurge con el romanticismo, impregnando a otras clases sociales, en cuanto a su aptitud, pero solo a las clases media alta y alta en cuanto a su práctica y que va creando uria moral y un modo de vida caballeresco que hace que socialmente sea exigible lo que jurídicamente se prohíbe, especialmente cuando los privilegios de la nobleza van siendo cada vez menores y se convierten en «ideales caballerescos», que tan bien supo plasmar Cervantes en el Quijote, incluso en el duelo, recogido en la II parte, cap. 56 («De la descomunal y nunca vista batalla que pasó entre D. Quijote de la Mancha y el lacayo Tosilos en la defensa de la hija de la dueña Doña. Rodríguez»). 